\title{
Correction to: Postoperative intestinal obstruction in patients with biliary atresia impedes biliary excretion and results in subsequent liver transplantation
}

\author{
Aitaro Takimoto ${ }^{1} \cdot$ Wataru Sumida $^{1} \cdot$ Hizuru Amano ${ }^{1} \cdot$ Chiyoe Shirota $^{1} \cdot$ Takahisa Tainaka $^{1} \cdot$ Kazuki Yokota $^{1}$. \\ Satoshi Makita ${ }^{1}$. Akihiro Yasui ${ }^{1}$ - Yoko Kanou ${ }^{1} \cdot$ Akinari Hinoki $^{1} \cdot$ Hiroo Uchida $^{1}$
}

Published online: 16 March 2021

(c) Springer-Verlag GmbH Germany, part of Springer Nature 2021

\section{Correction to: \\ Pediatric Surgery International (2021) 37:229-234 \\ https://doi.org/10.1007/s00383-020-04807-9}

The article Postoperative intestinal obstruction in patients with biliary atresia impedes biliary excretion and results in subsequent liver transplantation, written by Aitaro Takimoto, Wataru Sumida, Hizuru Amano, Chiyoe Shirota, Takahisa Tainaka, Kazuki Yokota, Satoshi Makita, Akihiro Yasui, Yoko Kanou, Akinari Hinoki, Hiroo Uchida, was originally published online on 3 January 2021 with Open Access under a "Creative Commons Attribution 4.0 International License, which permits use, sharing, adaptation, distribution and reproduction in any medium or format, as long as you give appropriate credit to the original author(s) and the source, provide a link to the Creative Commons licence, and indicate if changes were made. The images or other third party material in this article are included in the article's Creative Commons licence, unless indicated otherwise in a credit line to the material. If material is not included in the article's Creative Commons licence and your intended use is not permitted by statutory regulation or exceeds the permitted use, you will need to obtain permission directly from the copyright holder. To view a copy of this licence, visit http://creativecommons.org/licenses/by/4.0/'].

After publication in volume 37, issue 2, page 229-234 the author(s) decided to cancel the Open Access. Therefore, the copyright of the article has been changed on 16 February

The original article can be found online at https://doi.org/10.1007/ s00383-020-04807-9.

Hiroo Uchida

hiro2013@med.nagoya-u.ac.jp

1 Department of Pediatric Surgery, Nagoya University

Graduate School of Medicine, 65 Tsurumai,

Showa, Nagoya 466-8550, Japan
2021 to $\odot$ S Springer-Verlag GmbH Germany, part of Springer Nature 2021 with all rights reserved.

The original article has been corrected.

Publisher's Note Springer Nature remains neutral with regard to jurisdictional claims in published maps and institutional affiliations. 